\title{
Gallotannin causes differentiation and inflammation via ERK-1/-2 and p38 kinase pathways in rabbit articular chondrocytes
}

\author{
WON-KIL LEE, KI-WHA CHUNG, GWANG-HOON KIM and SONG-JA KIM \\ Department of Biological Sciences, College of Natural Sciences, Kongju National University, \\ Gongju, Chungnam 314-701, Republic of Korea
}

Received September 29, 2012; Accepted November 26, 2012

DOI: $10.3892 / \mathrm{mmr} .2012 .1204$

\begin{abstract}
Gallotannin (GT) is a type of tannic acid, derived from plant polyphenols, that is an agonist of plant defense mechanisms. Tannins have two types of structure; condensed tannins are a polymer of flavonoid units, while hydrolysable tannins are carbohydrates. GT is used in medical agents for its anti-viral, anti-bacterial and anti-parasitic effects. The present study investigated the effects of GT on differentiation and inflammation in rabbit articular chondrocytes. GT caused differentiation and inflammatory responses in the rabbit articular chondrocytes. GT treatment induced the expression of type II collagen and sulfated proteoglycan, as determined by western blot analysis and alcian blue staining, respectively, in a dose- and time-dependent manner. Additionally, treatment with GT increased the expression of cyclooxygenase-2 (COX-2) and the production of prostaglandin $\mathrm{E}_{2}\left(\mathrm{PGE}_{2}\right)$, as determined by western blot analysis and $\mathrm{PGE}_{2}$ assay. GT was confirmed to cause phosphorylation of ERK-1/-2 and p38 kinase. Inhibition of pERK with PD98059 promoted GT-induced type II collagen expression. However, the inhibition of p38 with SB203580 suppressed GT-induced COX-2 expression and $\mathrm{PGE}_{2}$ production. In summary, the results demonstrated that GT-induced ERK-1/-2 and p38 kinase have opposite effects on differentiation and inflammation in rabbit articular chondrocytes.
\end{abstract}

\section{Introduction}

Chondrocytes in cartilage are differentiated from mesenchymal cells during embryonic development $(1,2)$. They are the only cell type located in normal mature cartilage and they function to maintain extracellular matrix (ECM) integrity by synthesizing cartilage-specific ECM in sufficient quantities. This homeostasis is destroyed in degenerative diseases, including

Correspondence to: Professor Song-Ja Kim, Department of Biological Sciences, College of Natural Sciences, Kongju National University, 182 Shinkwan-Dong, Gongju, Chungnam 314-701, Republic of Korea

E-mail: ksj85@kongju.ac.kr

Key words: gallotannin, differentiation, inflammation osteoarthritis (OA) and rheumatoid arthritis (RA) (3). The biochemical and structural changes in chondrocytes and cartilage that characterize arthritis include the degradation of the cartilage matrix and insufficient ECM synthesis due to a loss of chondrocyte phenotype. OA is the most common form of joint disease that evolves from a local inflammatory disease into a chronic process with a variable degree of degeneration of the articular cartilage and inflammation. This ultimately exposes the underlying bone and results in pain and disability (4). The second type of arthritis, RA, is a destructive and inflammatory, polyarticular joint disease, with an etiology that remains to be clarified. RA is characterized massive synovial proliferation and subintimal infiltration of the inflammatory cells followed by the destruction of cartilage and bone (5).

Tannins are water-soluble polyphenols that are widely distributed in the plant kingdom, including in food grains and fruits (6). Based on their structural characteristics, tannins may be separated into four major groups: gallotannins (GTs), ellagitannins, complex tannins and condensed tannins. These tannins are thought to have notable biological and pharmacological activities $(7,8)$. The hydrolysable tannin, gallotannin, is a compound of the polygalloyl esters of glucose. Gallotannin is a type of tannic acid derived from plant polyphenols. Tannins have two types of structure; condensed tannins are a polymer of flavonoid units, while hydrolysable tannins are carbohydrates. The hydroxyl groups of the carbohydrate are partially or completely esterified with phenolic groups, including gallic acid. Hydrolysable tannins are hydrolyzed by weak acids or weak bases to produce carbohydrates and phenolic acids. These hydrolysable tannins are used in medical agents for their useful properties, including their anti-viral, anti-bacterial and anti-parasitic effects. GTs have been shown to exhibit diverse biological abilities, ranging from anti-inflammation to anti-oxidant effects $(9,10)$.

Cyclooxygenases (COXs) are known to exist in two isoforms, COX-1 and COX-2. In addition, the two COX isoforms were identified with a similar sequence (11). COX-1 is a constitutive enzyme located in the majority of mammalian cells (12). COX-2, however, is undetectable in the majority of normal tissues (13). COX-2 is an inducible enzyme that becomes abundant in activated macrophages and other cells at sites of inflammation as a result of various stimuli, including cytokines. Expression of COX-2 was demonstrated to increase prostaglandin $\mathrm{E}_{2}\left(\mathrm{PGE}_{2}\right)$ production $(14,15)$ and induce various 
inflammatory reactions (16). Mice that lack COX-2, but possess COX-1 expression, exhibit reduced bone resorption in response to parathyroid hormone $(\mathrm{PTH})$ or 1, 25-hydroxyl vitamin $\mathrm{D}_{3}(17)$. COX-2 may also have a role in bone formation as local or systemic injections of $\mathrm{PGE}_{2}$ stimulate bone formation $(18,19)$. COX-2 mediates the increase in lamellar bone formation that occurs as a response to mechanical strain $(20,21)$.

The mitogen-activated protein kinase (MAPK) cascades make up one of the major signaling systems by which cells transduce and integrate diverse intracellular signals. MAPKs are serine/threonine kinases that regulate a variety of processes, including cell growth, proliferation, apoptosis and extracellular matrix accumulation. The three MAPK subfamilies consist of extracellular signal-regulated kinases (ERKs), p38 kinases and c-Jun NH2-terminal kinases (JNKs) (22). Previous studies in articular chondrocytes indicated that NO caused apoptosis and dedifferentiation, which were mediated by the MAPK subtypes, ERK and p38 kinase (23). These MAP kinases play opposing roles; activated ERK-1/-2 induces dedifferentiation, COX-2 expression and NO-induced apoptosis inhibition, whereas p38 kinase signaling triggers apoptosis, COX-2 expression and maintains the differentiated states (24).

In the present study, ERK-1/-2 and p38 kinase are demonstrated to regulate GT-induced differentiation and inflammation of chondrocytes, respectively.

\section{Materials and methods}

Cell culture. Rabbit articular chondrocytes were isolated from cartilage slices obtained from 2-week-old New Zealand white rabbits using enzymatic digestion, as described previously (25). The cartilage slices were dissociated enzymatically for $6 \mathrm{~h}$ in $0.2 \%$ collagenase type II $(381 \mathrm{U} / \mathrm{mg}$ solid; Sigma Aldrich, Louis, MO, USA), in Dulbecco's modified Eagle's medium (DMEM; Gibco-BRL, Gaithersburg, MD, USA). Individual cells were suspended in DMEM supplemented with $10 \%(\mathrm{v} / \mathrm{v})$ fetal bovine-calf serum, $50 \mathrm{~g} / \mathrm{ml}$ streptomycin and $50 \mathrm{U} / \mathrm{ml}$ penicillin, after which they were plated on culture dishes at a density of $5 \times 10^{4}$ cells $/ \mathrm{cm}^{2}$. The medium was changed every 2 days following seeding and the cells reached confluence in $\sim 5$ days. At 3.5 days the cell cultures were treated with GT purchased from Sigma Aldrich and a stock solution (MW: $1701.23 \mathrm{mM}$ ) in DMSO was prepared and stored at $4^{\circ} \mathrm{C}$. The following pharmacological agents were added $1 \mathrm{~h}$ prior to the GT: SB203580 (Calbiochem, San Diego, CA, USA) to inhibit the p38 kinase and PD98059 (Calbiochem) to inhibit the MEK-1/-2 . The treated cells, which were cultured in complete medium for $24 \mathrm{~h}$, were used for further analysis, as indicated in each experiment. The study was approved by the ethics committee of Kongju National University, Gongju, Republic of Korea.

Western blot analysis. Whole cell lysates were prepared by extracting proteins, using a buffer containing $50 \mathrm{mM}$ Tris- $\mathrm{HCl}$, $150 \mathrm{mM} \mathrm{NaCl}, 1 \%$ Nonidet P-40 and $0.1 \%$ sodium dodecylsulfate (SDS) at $\mathrm{pH} 7.4$, supplemented with protease inhibitors [10 $\mathrm{g} / \mathrm{ml}$ leupeptin, $10 \mathrm{~g} / \mathrm{ml}$ pepstatin $\mathrm{A}, 10 \mathrm{~g} / \mathrm{ml}$ aprotinin and $1 \mathrm{mM}$ of 4-(2-aminoethyl)-benzenesulfonyl fluoride] and phosphatase inhibitors $\left(1 \mathrm{mM} \mathrm{NaF}\right.$ and $\left.1 \mathrm{mM} \mathrm{Na}_{3} \mathrm{VO}_{4}\right)$. The proteins were size-fractionated by SDS-polyacrylamide gel electrophoresis and transferred to a nitrocellulose membrane. The nitrocellulose sheet was then blocked with 3\% skimmed dry milk in Tris-buffered saline. The following antibodies were used: anti-COX-2 (Cayman Chemical, Ann Arbor, MI, USA), pp38 (Cell Signaling, Beverly, MA, USA), pERK, ERK-2 and p38 (Santa Cruz Biotechnology Inc., Santa Cruz, CA, USA) and type II collagen (Chemicon, Temecula, CA, USA). The western blot samples were developed using a peroxidase-conjugated secondary antibody on a chemiluminescence system.

Alcian blue staining assay. The cells were fixed with $95 \%$ methanol at $-20^{\circ} \mathrm{C}$ for $2 \mathrm{~min}$ and stained with $0.1 \%$ alcian blue in $0.1 \mathrm{M} \mathrm{HCl}$ overnight. The chondrocytes were washed three times with PBS buffer and $6 \mathrm{M}$ guanidine $\mathrm{HCl}$ was added for $6 \mathrm{~h}$. The production level of sulfated proteoglycan was measured at $620 \mathrm{~nm}$ by enzyme-linked immunosorbent assay (ELISA).

$P G E_{2}$ assay. $\mathrm{PGE}_{2}$ production was determined by measuring the levels of cellular and secreted $\mathrm{PGE}_{2}$ using an assay kit (Amersham Pharmacia Biotech, Piscataway, NJ, USA). Briefly, chondrocytes were seeded in standard 96-well microtiter plates at $2 \times 10^{4}$ cells/well. Following addition of the indicated pharmacological reagents, the supernatant was used to quantify the amount of $\mathrm{PGE}_{2}$, according to the manufacturer's protocol. The $\mathrm{PGE}_{2}$ levels were calculated using a $\mathrm{PGE}_{2}$ standard curve.

Immunohistochemistry. Rabbit joint cartilage explants were fixed in $4 \%$ paraformaldehyde in PBS for $24 \mathrm{~h}$ at $4^{\circ} \mathrm{C}$, washed with PBS, dehydrated in ethanol, embedded in paraffin and sliced into $4-\mu \mathrm{m}$ sections, as described previously (26). The sections were stained by standard procedures, using antibodies against type II collagen and COX-2, then alcian blue staining followed by visualization by development with a kit purchased from Dako (Carpinteria, CA, USA), following the manufacturer's instructions.

Immunofluorescence staining. Expression and distribution of type II collagen and COX-2 in rabbit articular chondrocytes were determined by indirect immunofluorescence microscopy, as described previously (26). Briefly, chondrocytes were fixed with $3.5 \%$ paraformaldehyde in PBS for $10 \mathrm{~min}$ at room temperature. The cells were permeabilized and blocked with $0.1 \%$ Triton X-100 and 5\% fetal calf serum in PBS for $30 \mathrm{~min}$. The fixed cells were washed and incubated for $1 \mathrm{~h}$ with antibodies $(10 \mathrm{~g} / \mathrm{ml})$ against type II collagen and COX-2. The cells were washed, incubated with rhodamine- or fluorescein-conjugated secondary antibodies for $30 \mathrm{~min}$ and observed under a fluorescence microscope.

Reverse transcription (RT)-PCR. Primary cultured chondrocytes were treated with GT. Total RNA was isolated from the cells and reverse transcribed with a Maxime RT-PCR PreMix kit (Intron Biotechnology, Seoul, Korea). The following primers (based on the sequences of the rabbit type II collagen and COX-2) and conditions were used for the PCR: Type II collagen (370-bp product, annealing temperature $45^{\circ} \mathrm{C}$, 30 cycles) sense, 5'-GAC CCC ATG CAG TAC ATG CG-3' and antisense, 5'-AGC CGC CAT TGA TGG TCT CC-3'; COX-2 
A

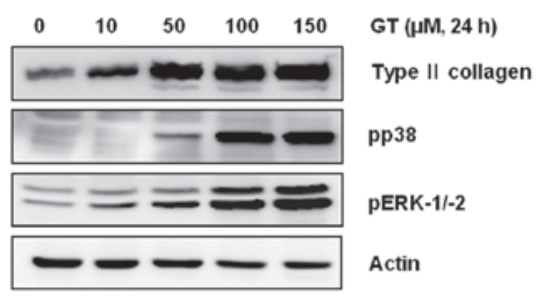

C

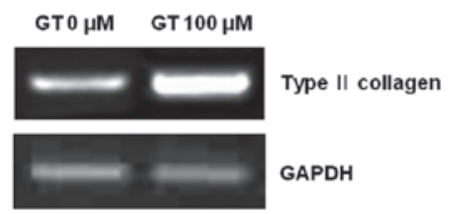

B

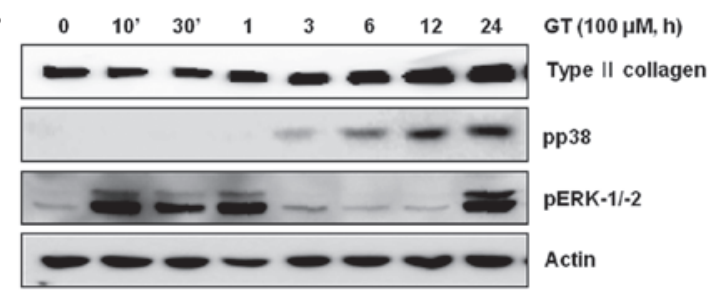

D

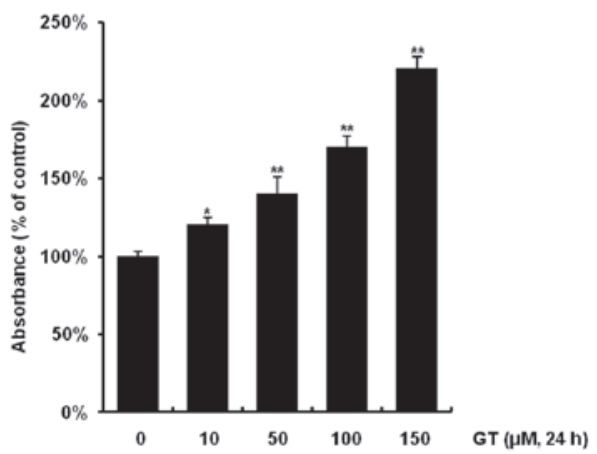

Figure 1. Gallotannin (GT) causes differentiation in rabbit articular chondrocytes. (A) Rabbit articular chondrocytes were treated with $10,50,100$ or $150 \mu \mathrm{M}$ GT for $24 \mathrm{~h}$ and subjected to western blot analysis with antibodies for type II collagen, pERK, pp38 and actin. (B) Chondrocytes were treated with $100 \mu \mathrm{M}$ GT for the indicated time periods. Western blot analysis of the expression of type II collagen, pERK, pp38 and actin was performed. Expression of $\beta$-actin was used as a loading control. (C) Articular chondrocytes were treated with $100 \mu \mathrm{M}$ GT for $24 \mathrm{~h}$ or left untreated. Expression of type II collagen and GAPDH was detected by RT-PCR. Expression of GAPDH was used as a loading control. (D) Rabbit articular chondrocytes were treated with 10,50, 100 or $150 \mu \mathrm{M}$ GT for $24 \mathrm{~h}$. Accumulation of sulgated proteoglycan was determined by alcian blue staining. The data represent a typical experiment, whereby similar results were obtained from three experiments. " $\mathrm{p}<0.05$ and ${ }^{* *} \mathrm{p}<0.001$, compared with untreated cells. RT-PCR, reverse transcription PCR.

(282 bp product, annealing temperature $45^{\circ} \mathrm{C}, 30$ cycles) sense, 5'-TCA GCC ACG CAG CAA ATC CT-3' and antisense, 5'-AGC CGC CAT TGA TGG TCT CC-3'. GAPDH was amplified for control and normalization purposes using the following primers and conditions: (299-bp product, annealing temperature $45^{\circ} \mathrm{C}, 30$ cycle) sense, 5'-TCA CCA TCT TCC AGG AGC GA-3' and antisense, 5'-CAC AAT GCC GAA GTG GTC GT-3'.

Data analysis and statistics. All results were expressed as the mean $\pm \mathrm{SE}$, calculated from the specified number of determinations. A Student's t-test was used to compare individual treatments with their respective control values. $\mathrm{P}<0.05$ was considered to indicate a statistically significant difference.

\section{Results}

GT induces differentiation in rabbit articular chondrocytes GT has known biological properties, including anti-cancer, anti-inflammation and anti-oxidant effects $(27,28)$. First, the effects of GT on differentiation in articular chondrocytes were examined. Various concentrations of the GT treatment (10-150 $\mu \mathrm{M})$ increased type II collagen expression and activation of ERK-1/-2 and p38 kinase in a dose-dependent manner, as determined by western blotting (Fig. 1A). When cells were treated with $100 \mu \mathrm{M}$ GT, type II collagen expression was increased in a time-dependent manner, while ERK-1/-2 phosphorylation was transiently increased, as determined by the phosphorylation status of the protein (Fig. 1B). Levels of ERK-1/-2 phosphorylation began to increase at $10 \mathrm{~min}$, reached peak levels at $1 \mathrm{~h}$ and $24 \mathrm{~h}$ and decreased thereafter. Phosphorylation of p38 was increased in a time-dependent manner (Fig. 1B). As expected, transcription levels of type II collagen were increased, as determined by RT-PCR (Fig. 1C). Consistent with the expression pattern of type II collagen, GT treatment led to a dose-dependent decrease in the accumulation of sulfated proteoglycan (Fig. 1D). Overall, GT significantly increased the expression of type II collagen and the phosphorylation of ERK-1/-2 and p38 kinase in the chondrocytes, in a dose- and time- dependent manner.

GT causes inflammation in chondrocytes. Previous studies showed that expression of COX-2 increased $\mathrm{PGE}_{2}$ (15) and that $\mathrm{PGE}_{2}$ induced various inflammation reactions (16). In the present study, chondrocytes were treated with varying concentrations of GT (Fig. 2A) or with $100 \mu \mathrm{M}$ GT for the indicated period (Fig. 2B). As shown in Fig. 2A and B, GT caused COX-2 expression in a dose- and time-dependent manner, as determined by western blotting. Transcription levels of COX-2 were increased with the $100 \mu \mathrm{M}$ GT treatment, as determined by RT-PCR (Fig. 2C). As expected, similar results were observed when $\mathrm{PGE}_{2}$ production was quantified by $\mathrm{PGE}_{2}$ assay (Fig. 2D). GT exhibited production of $\mathrm{PGE}_{2}$ that was 5.6-, 6.3-, 10.2- and 16.7-fold more than the control in the rabbit articular chondrocytes. These results demonstrated that GT caused inflammation of articular chondrocytes in primary cultured cells.

GT regulates differentiation and inflammation via the ERK-1/-2 and 38 kinase pathways in rabbit articular chondrocytes. The present study examined the possible modulation of GT-induced activation of the MAP kinase subtypes ERK-1/-2 and p38 kinase on GT-induced differentiation and inflammation. Inhibition of GT-induced p38 kinase activation with $20 \mu \mathrm{M}$ 
$\mathbf{A}$

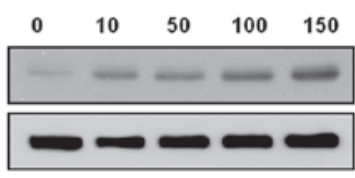

C

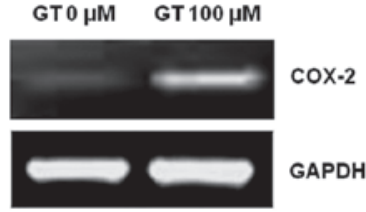

B

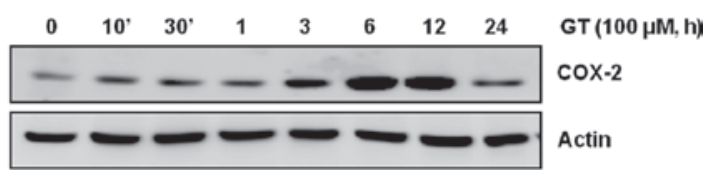

D

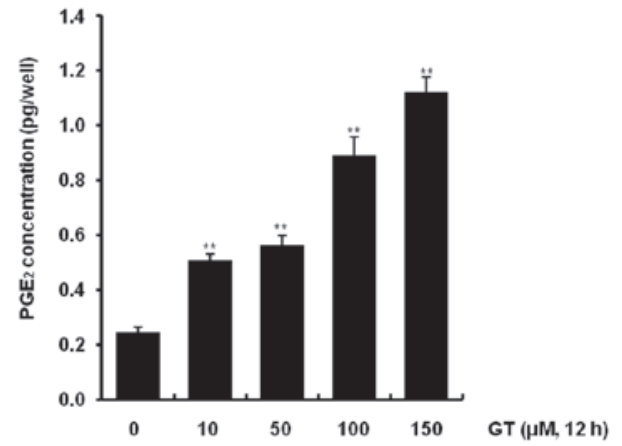

Figure 2. GT increases COX-2 expression and $\mathrm{PGE}_{2}$ production in rabbit articular chondrocytes. (A) Rabbit articular chondrocytes were treated with 10, 50, 100 or $150 \mu \mathrm{M}$ GT for $12 \mathrm{~h}$ and subjected to western blot analysis with antibodies for COX-2 and actin. (B) Chondrocytes were treated with $100 \mu \mathrm{M}$ GT for the indicated time periods. Expression of COX-2 was analyzed by western blot analysis. Expression of $\beta$-actin was used as a loading control. (C) Articular chondrocytes were treated with $100 \mu \mathrm{M}$ GT for $12 \mathrm{~h}$ or left untreated. Expression of COX-2 and GAPDH were detected by RT-PCR. Expression of GAPDH

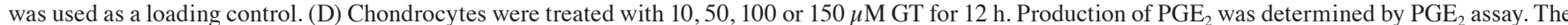
data represent a typical result and average values, with standard deviations from independent experiments. ${ }^{*} \mathrm{p}<0.05$ and ${ }^{* * *} \mathrm{p}<0.001$ compared with untreated cells. GT, gallotannin; RT-PCR, reverse transcription PCR.
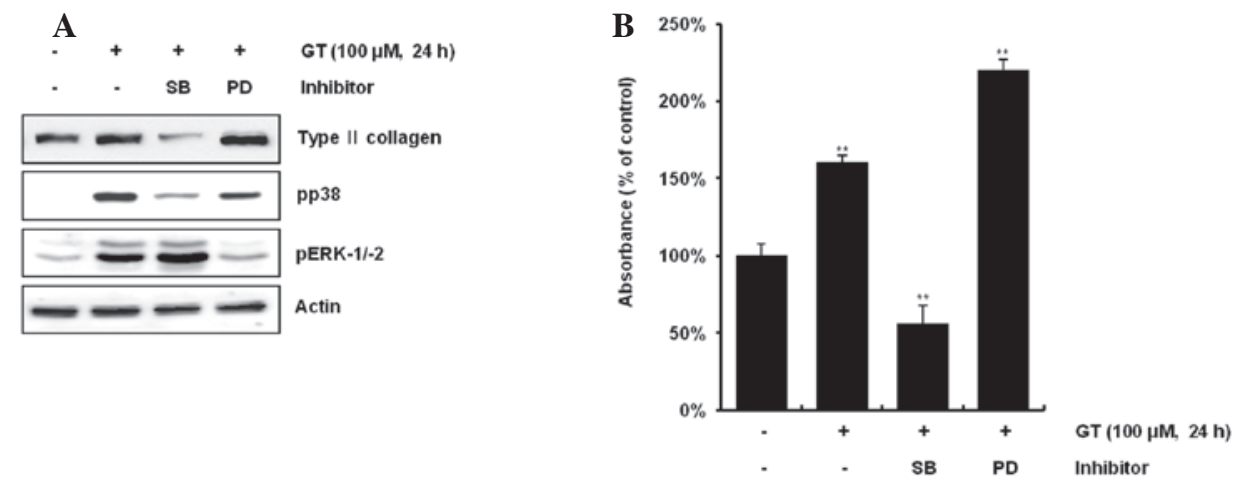

Figure 3. GT regulates type II collagen expression via the ERK-1/-2 and p38 kinase pathways in rabbit articular chondrocytes. (A) Articular chondrocytes were treated with $100 \mu \mathrm{M}$ GT, PD98059 (PD) or SB203580 (SD) for $24 \mathrm{~h}$ or left untreated. Expression of type II collagen was analyzed by western blot analysis. Expression of $\beta$-actin was used as a loading control. (B) Rabbit articular chondrocytes were treated with $100 \mu \mathrm{M}$ GT, PD98059 or SB203580 for $24 \mathrm{~h}$ or left untreated. Accumulation of sulfated proteoglycan was determined by alcian blue staining. The data represent a typical experiment, whereby similar results were obtained from three experiments. " $\mathrm{p}<0.05$ and ${ }^{* *} \mathrm{p}<0.001$ compared with untreated cells. GT, gallotannin.
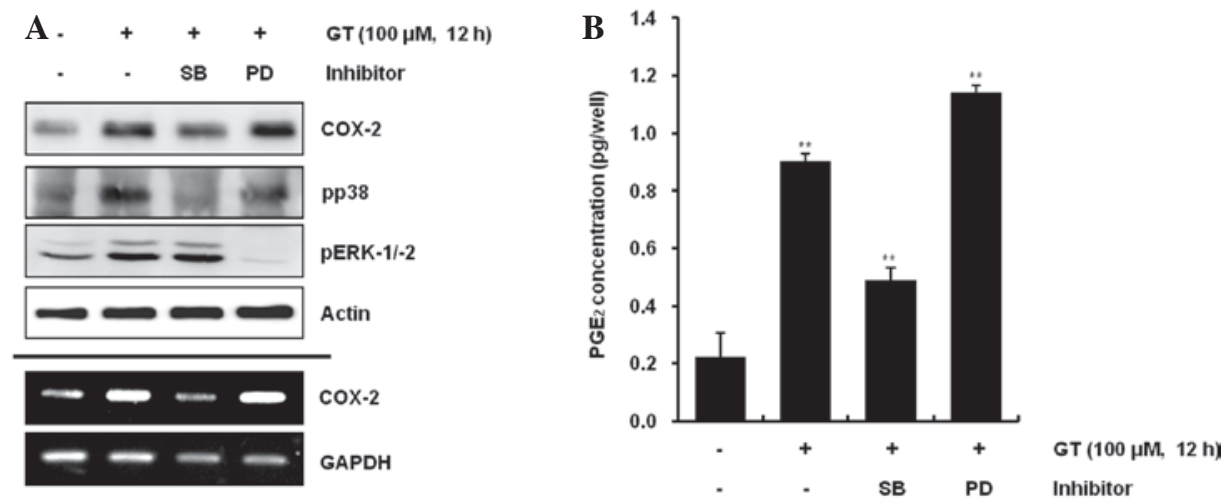

Figure 4. GT regulates COX-2 expression and $\mathrm{PGE}_{2}$ activation via the ERK-1/-2 and p38 kinase pathways in rabbit articular chondrocytes. (A) Articular chondrocytes were treated with $100 \mu \mathrm{M}$ GT, PD98059 (PD) or SB203580 (SB) for $12 \mathrm{~h}$ or left untreated. Expression of COX-2 was analyzed by western blot analysis. Expression of $\beta$-actin was used as a loading control. (B) Rabbit articular chondrocytes were treated with $100 \mu \mathrm{M}$ GT, PD98059 or SB203580 for $24 \mathrm{~h}$ or left untreated. Productions of $\mathrm{PGE}_{2}$ were determined by $\mathrm{PGE}_{2}$ assay. The data represent a typical experiment, whereby similar results were obtained from three experiments. ${ }^{p}<0.05$ and ${ }^{* * *} \mathrm{p}<0.001$ compared with untreated cells. GT, gallotannin. 

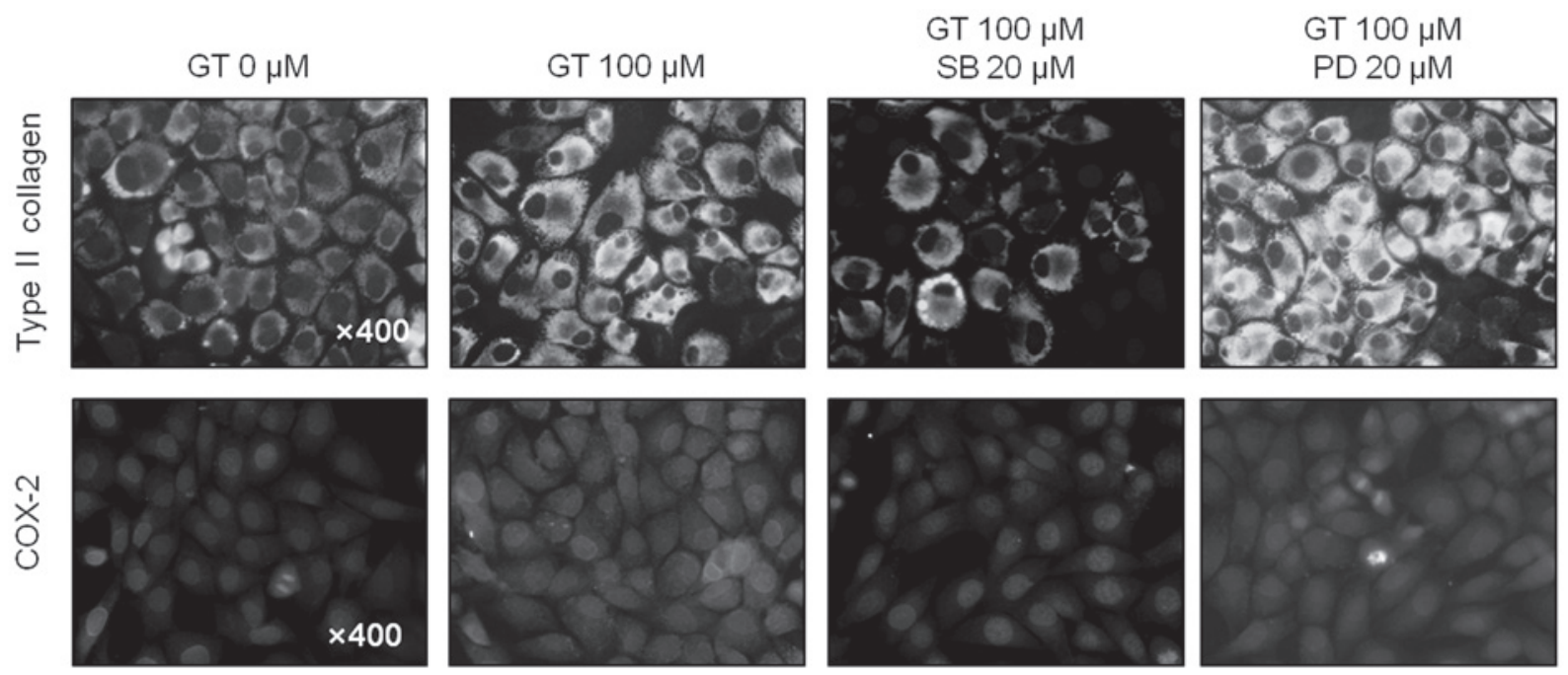

Figure 5. ERK-1/-2 and p38 kinase pathway regulate GT-induced type II collagen and COX-2 expression in rabbit articular chondrocytes. Articular chondrocytes were treated with $100 \mu \mathrm{M} \mathrm{GT}, 20 \mu \mathrm{M}$ PD98059 (PD) or $20 \mu \mathrm{M} \mathrm{SB} 203580$ (SB) for $24 \mathrm{~h}$ or left untreated. Expression of type II collagen and COX-2 was identified by immunofluorescence microscopy (x400). The cell nuclei were observed by 4,6-diamidino-2-phenylindole (DAPI) staining of the cell. GT, gallotannin.
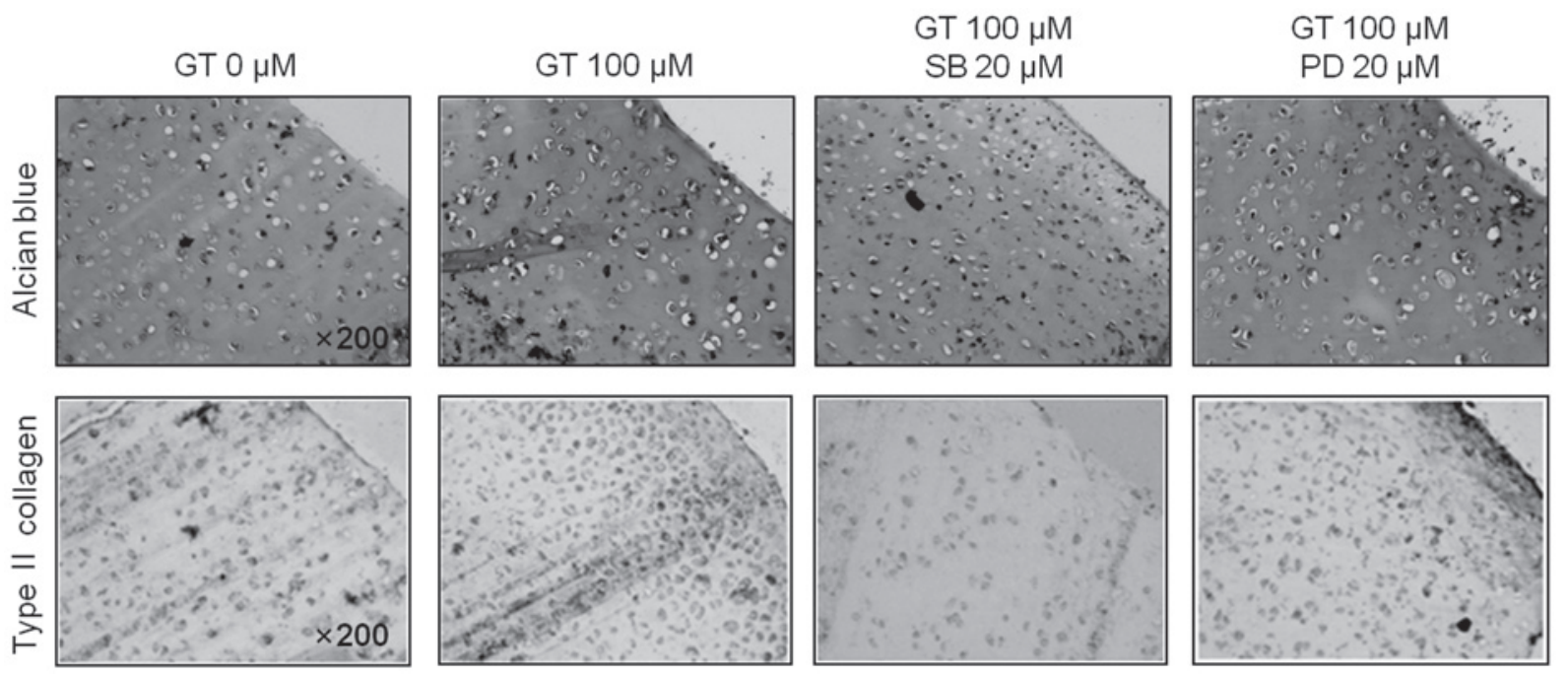

Figure 6. GT causes differentiation and inflammation of articula chondrocytes via the ERK-1/-2 and p38 kinase pathway. Treatment of GT causes differentiation and inflammation of the rabbit cartilage. Cartilage explants were treated with $100 \mu \mathrm{M} \mathrm{GT}, 20 \mu \mathrm{M}$ PD98059 (PD) or $20 \mu \mathrm{M} \mathrm{SB} 203580$ (SB) for $24 \mathrm{~h}$ or left untreated. Type II collagen was detected by immunohistochemical staining (x200). Sulfated proteoglycan was detected by alcian blue staining (x200). The data represent the results of typical experiments conducted at least four times. GT, gallotannin.

SB203580 reduced differentiation and inflammation, whereas inhibition of GT-induced ERK-1/-2 with $20 \mu \mathrm{M}$ PD98059 resulted in the potentiation of differentiation and inflammation (Figs. 3A and 4A). Consistent with the expression patterns of type II collagen and COX-2, inhibition of GT-induced p38 kinase activation led to a decrease in the accumulation of sulfated proteoglycan and $\mathrm{PGE}_{2}$ production, whereas inhibition of GT-induced ERK-1/-2 promoted the accumulation of sulfated proteoglycan and $\mathrm{PGE}_{2}$ production, as determined by alcian blue staining and $\mathrm{PGE}_{2}$ assays, respectively (Figs. 3B and 4B). Consistent with the western blot data, the immunostaining results also showed that inhibition of p38 kinase markedly blocked type II collagen and COX-2 expression levels, whereas ERK-1/-2 inhibition caused a significant increase in type II collagen and COX-2 expression (Fig. 5). Similar results were observed when inhibition of GT caused ERK-1/-2 and when p38 kinase had the opposite effect on GT-induced differentiation, as determined by immunohistochemical staining (Fig. 6). The results collectively indicate that GT-induced ERK-1/-2 and p38 kinase had opposite effects on differentiation and inflammation in rabbit articular chondrocytes.

\section{Discussion}

GT is a type of tannic acid derived from plant polyphenols, that is usually an agonist of plant defense mechanisms. The tannin GT is used in medical agents for its anti-viral, anti-bacterial and anti-parasitic properties (27-29). GT has been shown to exhibit diverse biological effects, including the inhibition of chemokine and inflammatory cytokine expression in A549 cells (30). 
Generic cells develop into specific cell types by cell differentiation as a response to specific triggers from the body or the cells themselves. This process allows multicellular adult organisms, containing hundreds of varying types of cells, to develop from a single-celled zygote. Cell differentiation also has roles in the functions of numerous organisms, particularly complex mammals, throughout their lives. A sequential process of differentiation is commonly known to show indications of chondrogenic differentiation within fibrous, mesenchymal tissue, marked by the onset of type II collagen. The next stage of the process is characterized by the appearance of transitory, fibrocartilaginous cells expressing collagen types II and III. Chondrocyte phenotypes are classically categorized, mainly by the subtyping of collagen gene expression. Thus, the expression of the alternative splice variant of type II collagen characterizes chondroprogenitor cells. Mature chondrocytes express the typical cartilage collagen types II, IX and XI, as well as aggrecan and link protein. Chick chondrocytes are able to undergo post-hypertrophic differentiation into osteoblast-like cells, expressing type I collagen. The present study has shown that GT significantly induced type II collagen expression in rabbit articular chondrocytes following $24 \mathrm{~h}$ of treatment in a dose-dependent manner, as examined by western blot analysis and RT-PCR assays. Type II collagen is a known marker of differentiation in chondrocytes.

The metabolites of COX activity have long been suspected to be important in skeletal reparative processes. The administration of $\mathrm{PGE}_{2}$ has increased the rate of fracture healing in several animal models $(31,32)$, indicating that the metabolites of COXs may be necessary for efficient bone healing. The effect that $\mathrm{PGE}_{2}$ has on chondrocytes is dependent on physiological conditions, the microenvironment and the culture system $(33,34) . \mathrm{PGE}_{2}$ exerts anabolic effects, including proteoglycan and type II collagen synthesis, as well as catabolic effects, including the enhancement of matrix degradation (35-37). For example, $\mathrm{PGE}_{2}$ has been shown to promote chondrocyte differentiation and increase type II collagen expression in inflammation $(19,21,34,37)$. In the results of our previous study, it was observed that the addition of exogenous $\mathrm{PGE}_{2}$ did not affect chondrocyte dedifferentiation (38). GT decreased nitric oxide (NO) production, through inhibition of nuclear factor (NF)- $\kappa \mathrm{B}$ in macrophages (39). Generally, an increase in COX-2 expression and $\mathrm{PGE}_{2}$ products induces activation of NF- $\kappa \mathrm{B}$. However, the present study demonstrated that GT increased COX-2 expression and $\mathrm{PGE}_{2}$ production in articular chondrocytes (Fig. 2). These results suggested that GT induced the inflammation in the chondrocytes.

Mitogen-activated protein kinase (MAPK) cascades have been shown to play key roles in the transduction of extracellular signals to cell responses. The MAPK families that have been clearly characterized in mammalian cells are classical MAPK (also known as ERK), C-Jun N-terminal kinse/stress-activated protein kinase (JNK/SAPK) and p38 kinase (40). The MAPK pathways relay, amplify and integrate signals from a wide range of stimuli prior to eliciting an appropriate physiological response that may include cell proliferation, differentiation, development, inflammatory responses and apoptosis in mammalian cells (41). Cellular stresses, including UV irradiation, heat shock, high osmotic stress, lipopolysaccharide, protein synthesis inhibitors, proinflammatory cytokines and certain mitogens activate the p38 MAPK families. p38 MAPK appears to play a major role in apoptosis, differentiation, survival, proliferation, development and inflammation. Previously it was reported that $\mathrm{p} 38$ was involved in the differentiation processes of various vertebrate cells, including adipocytes, cardiomyocytes, chondroblasts, erythroblasts, myoblasts and neurons (42). The ERK family (p42/44 MAPK) is known to be an intracellular checkpoint for cellular mitogenesis. In cultured cell lines, mitogenic stimulation by growth factors correlates with stimulation of p42/44 MAPK. When components of the ERK signaling pathway are interfered with using dominant negative mutants or antisense constructs for raf-1 or ERK1, significant inhibition of cell proliferation is revealed. In another study, MAPKs have been shown to play opposing roles, with activated ERK-1/-2 inducing dedifferentiation, COX-2 expression and the inhibition of NO-induced apoptosis, while p38 kinase signaling triggers apoptosis, COX-2 expression and maintains the differentiated states (24). In the present study, GT caused an increase in differentiation of the chondrocyte phenotype, as demonstrated by the increase in type II collagen expression and sulfated proteoglycan synthesis in a time- and dose-dependent manner. Moreover, GT induced COX-2 expression and $\mathrm{PGE}_{2}$ production. Inhibition of ERK-1/-2 with PD98059 potentiated GT-induced type II collagen and COX-2 expression, whereas inhibition of p38 kinase with SB203580 decreased type II collagen and COX-2 expression (Figs. 3 and 4). GT-induced type II collagen and COX-2 expression and $\mathrm{PGE}_{2}$ production are modulated by ERK-1/-2 and p38 kinase signaling $(43,44)$.

In summary, the data from the present study have demonstrated that ERK-1/-2 and p38 kinase oppositely regulate GT-induced differentiation and inflammation in rabbit articular chondrocytes.

\section{Acknowledgements}

This study was supported by a National Research Foundation of Korea (NRF) grant, funded by the Korean Government (MEST; 2011-0027473 and 2012-0004359).

\section{References}

1. DeLise AM, Fischer L and Tuan RS: Cellular interactions and signaling in cartilage development. Osteoarthritis Cartilage 8: 309-334, 2000

2. Sandell LJ and Adler P: Developmental patterns of cartilage. Front Biosci 4: D731-D742, 1999.

3. Sandell LJ and Aigner T: Articular cartilage and changes in arthritis. An introduction: cell biology of osteoarthritis. Arthritis Res 3: 107-113, 2001.

4. Feldmann M: Pathogenesis of arthritis: recent research progress. Nat Immunol 2: 771-773, 2001.

5. Feldmann M, Brennan FM and Maini RN: Rheumatoid arthritis. Cell 85: 307-310, 1996.

6. Erdèlyi K, Kiss A, Bakondi E, Bai P, Szabó C, Gergely P, Erdödi F and Virag L: Gallotannin inhibits the expression of chemokines and inflammatory cytokines in A549 cells. Mol Pharmacol 68: 895-904, 2005.

7. Li W, Zhang J, Flechner L, Hyun T, Yam A, Franke TF and Pierce JH: Protein kinase C-alpha overexpression stimulates Akt activity and suppresses apoptosis induced by interleukin 3 withdrawal. Oncogene 18: 6564-6572, 1999.

8. Rapizzi E, Fossati S, Moroni F and Chiarugi A: Inhibition of poly(ADP-ribose) glycohydrolase by gallotannin selectively up-regulates expression of proinflammatory genes. Mol Pharmacol 66: 890-898, 2004. 
9. Feldman KS, Sahasrabudhe K, Lawlor MD, Wilson SL, Lang CH and Scheuchenzuber WJ: In vitro and in vivo inhibition of LPS-stimulated tumor necrosis factor-alpha secretion by the gallotannin beta-D-pentagalloylglucose. Bioorg Med Chem Lett 11: $1813-1815,2001$.

10. Hagerman AE, Riedl KM and Rice RE: Tannins as biological antioxidants. Basic Life Sci 66: 495-505, 1999.

11. Smith WL, DeWitt DL and Garavito RM: Cyclooxygenases: structural, cellular, and molecular biology. Annu Rev Biochem 69: 145-182, 2000 .

12. Dubois RN, Abramson SB, Crofford L, Gupta RA, Simon LS Van De Putte LB and Lipsky PE: Cyclooxygenase in biology and disease. FASEB J 12: 1063-1073, 1998.

13. Wu KK: Inducible cyclooxygenase and nitric oxide synthase. Adv Pharmacol 33: 179-207, 1995.

14. Goldring MB and Berenbaum F: Human chondrocyte culture models for studying cyclooxygenase expression and prostaglandin regulation of collagen gene expression. Osteoarthritis Cartilage 7: 386-388, 1999.

15. Namkoong S, Lee SJ, Kim CK, Kim YM, Chung HT, Lee H, Han JA, Ha KS, Kwon YG and Kim YM: Prostaglandin E2 stimulates angiogenesis by activating the nitric oxide/cGMP pathway in human umbilical vein endothelial cells. Exp Mol Med 37: 588-600, 2005

16. Smith WL, Garavito RM and DeWitt DL: Prostaglandin endoperoxide $\mathrm{H}$ synthases (cyclooxygenases)-1 and -2 . J Biol Chem 271: 33157-33160, 1996 .

17. Okada Y, Lorenzo JA, Freeman AM, Tomita M, Morham SG, Raisz LG and Pilbeam CC: Prostaglandin G/H synthase-2 is required for maximal formation of osteoclast-like cells in culture. J Clin Invest 105: 823-832, 2000.

18. Suponitzky I and Weinreb M: Differential effects of systemic prostaglandin E2 on bone mass in rat long bones and calvariae. J Endocrinol 156: 51-57, 1998

19. Weinreb M, Suponitzky I and Keila S: Systemic administration of an anabolic dose of $\mathrm{PGE}_{2}$ in young rats increases the osteogenic capacity of bone marrow. Bone 20: 521-526, 1997.

20. Duncan RL and Turner CH: Mechanotransduction and the functional response of bone to mechanical strain. Calcif Tissue Int 57: 344-358, 1995

21. Forwood MR: Inducible cyclo-oxygenase (COX-2) mediates the induction of bone formation by mechanical loading in vivo J Bone Miner Res 11: 1688-1693, 1996.

22. Park EH, Kang SS, Lee YS, Kim SJ, Jin EJ, Tak EN and Sonn JK Integrity of the cortical actin ring is required for activation of the $\mathrm{PI} 3 \mathrm{~K} / \mathrm{Akt}$ and $\mathrm{p} 38 \mathrm{MAPK}$ signaling pathways in redifferentiation of chondrocytes on chitosan. Cell Biol Int 32: 1272-1278, 2008.

23. Kim SJ, Kim HG, Oh CD, Hwang SG, Song WK, Yoo YJ, Kang SS and Chun JS: p38 kinase-dependent and -independent Inhibition of protein kinase $\mathrm{C}$ zeta and -alpha regulates nitric oxide-induced apoptosis and dedifferentiation of articular chondrocytes. J Biol Chem 277: 30375-30381, 2002.

24. Kim SJ, Ju JW, Oh CD, Yoon YM, Song WK, Kim JH, Yoo YJ, Bang OS, Kang SS and Chun JS: ERK-1/2 and p38 kinase oppositely regulate nitric oxide-induced apoptosis of chondrocytes in association with p53, caspase-3, and differentiation status. J Biol Chem 277: 1332-1339, 2002.

25. Yoon YM, Kim SJ, Oh CD, Ju JW, Song WK, Yoo YJ, Huh TL and Chun JS: Maintenance of differentiated phenotype of articular chondrocytes by protein kinase $\mathrm{C}$ and extracellular signal-regulated protein kinase. J Biol Chem 277: 8412-8420, 2002.

26. Ryu JH, Kim SJ, Kim SH, Oh CD, Hwang SG, Chun CH, Oh SH, Seong JK, Huh TL and Chun JS: Regulation of the chondrocyte phenotype by beta-catenin. Development 129: 5541-5550, 2002.

27. Lü L, Liu SW, Jiang SB and Wu SG: Tannin inhibits HIV-1 entry by targeting gp41. Acta Pharmacol Sin 25: 213-218, 2004.
28. Lu Y, Jiang F, Jiang H, Wu K, Zheng X, Cai Y, Katakowski M, Chopp $M$ and To SS: Gallic acid suppresses cell viability, proliferation, invasion and angiogenesis in human glioma cells. Eur J Pharmacol 641: 102-107, 2010.

29. Akiyama H, Fujii K, Yamasaki O, Oono T and Iwatsuki K: Antibacterial action of several tannins against Staphylococcus aureus. J Antimicrob Chemother 48: 487-491, 2001.

30. Yu SM, Gweon EJ, Chung KW, Kim KH, Cho HS and Kim SJ: Gallotannin regulates apoptosis and COX-2 expression via Akt and p38kinase pathway in human lung cancer cell line, A549. Animal Cells and Systems 16: 366-375, 2012.

31. Keller J: Effects of indomethacin and local prostaglandin E2 on fracture healing in rabbits. Dan Med Bull 43: 317-329, 1996.

32. Norrdin RW and Shih MS: Systemic effects of prostaglandin E2 on vertebral trabecular remodeling in beagles used in a healing study. Calcif Tissue Int 42: 363-368, 1988.

33. Amin AR, Dave M, Attur M and Abramson SB: COX-2, NO, and cartilage damage and repair. Curr Rheumatol Rep 2: 447-453, 2000

34. Schwartz Z, Gilley RM, Sylvia VL, Dean DD and Boyan BD: The effect of prostaglandin E2 on costochondral chondrocyte differentiation is mediated by cyclic adenosine $3^{\prime}, 5^{\prime}$-monophosphate and protein kinase C. Endocrinology 139: 1825-1834, 1998.

35. Abramson SB: The role of COX-2 produced by cartilage in arthritis. Osteoarthritis Cartilage 7: 380-381, 1999.

36. Goldring MB, Birkhead JR, Suen LF, Yamin R, Mizuno S, Glowacki J, Arbiser JL and Apperley JF: Interleukin-1 beta-modulated gene expression in immortalized human chondrocytes. J Clin Invest 94: 2307-2316, 1994.

37. Goldring MB, Suen LF, Yamin R and Lai WF: Regulation of collagen gene expression by prostaglandins and interleukin-lbeta in cultured chondrocytes and fibroblasts. Am J Ther 3: 9-16, 1996.

38. Lee WK, Yu SM, Cheong SW, Sonn JK and Kim SJ: Ectopic expression of cyclooxygenase-2-induced dedifferentiation in articular chondrocytes. Exp Mol Med 40: 721-727, 2008.

39. Kim MS, Park SB, Suk K, Kim IK, Kim SY, Kim JA, Lee SH and Kim SH: Gallotannin isolated from Euphorbia species, 1,2,6-tri$\mathrm{O}$-galloyl-beta-D-allose, decreases nitric oxide production through inhibition of nuclear factor-kappa B and downstream inducible nitric oxide synthase expression in macrophages. Biol Pharm Bull 32: 1053-1056, 2009.

40. Widmann C, Gibson S, Jarpe MB and Johnson GL: Mitogenactivated protein kinase: conservation of a three-kinase module from yeast to human. Physiol Rev 79: 143-180, 1999.

41. Zhang W and Liu HT: MAPK signal pathways in the regulation of cell proliferation in mammalian cells. Cell Res 12: 9-18, 2002

42. Houde M, Laprise P, Jean D, Blais M, Asselin C and Rivard N: Intestinal epithelial cell differentiation involves activation of $\mathrm{p} 38$ mitogen-activated protein kinase that regulates the homeobox transcription factor CDX2. J Biol chem 276: 21885-21894, 2001.

43. Guan Z, Buckman SY, Miller BW, Springer LD and Morrison AR Interleukin-1beta-induced cyclooxygenase- 2 expression requires activation of both c-Jun NH2-terminal kinase and p38 MAPK signal pathways in rat renal mesangial cells. J Biol Chem 273 28670-28676, 1998.

44. Matsuura H, Sakaue M, Subbaramaiah K, Kamitani H, Eling TE, Dannenberg AJ, Tanabe T, Inoue H, Arata J and Jetten AM: Regulation of cyclooxygenase-2 by interferon gamma and transforming growth factor alpha in normal human epidermal keratinocytes and squamous carcinoma cells. Role of mitogen-activated protein kinases. J Biol Chem 274: 29138-29148, 1999. 